\title{
Dermatogenic enteropathy
}

JANET MARKS AND SAM SHUSTER

From the University Department of Dermatology, Royal Victoria Infirmary, Newcastle upon Tyne

SUMMARY Steatorrhoea has been found in a large proportion of patients with inflammatory $\frac{D}{2}$ dermatoses, especially eczema and psoriasis. It is due to the rash itself and disappears rapidly $\vec{\bullet}$ after topical treatment of the skin. This particular enteropathy, unlike that associated with dermatitis herpetiformis, is not accompanied by an alteration in the stereomicroscopic appearance of the small bowel mucosa. The mechanism is not known. It is important to differentiate dermatogenic enteropathy from gluten sensitivity which has produced a rash, as in the former condition a gluten-free diet is not indicated.

Dermatogenic enteropathy (Shuster and Marks, 1965 ) is an entity which is best understood in the context of the four known associations between skin and gut abnormalities (Shuster, 1967a and b; Shuster and Marks, 1970). These are: when malabsorption causes a rash, as in tropical sprue and 'idiopathic' steatorrhoea (group I); when skin disease causes malabsorption (dermatogenic enteropathy (group II); when skin and gut lesions are both due to the same pathological process as in the collagenoses (group III); and (group IV) when skin and gut lesions are indirectly related, as in dermatitis herpetiformis, which is associated with the coeliac syndrome more often than would be expected by chance but not in any of the three previous instances.

It can be seen that dermatogenic enteropathy differs fundamentally from other forms of malabsorption associated with skin disease in that it is caused by the rash itself, and some of the evidence for this has been presented and discussed already (Shuster and Marks, 1965; Shuster, 1967a and b; Marks, 1968; Shuster, $1968 \mathrm{a}$ and b; Marks, Shuster, and Watson, 1970; Shuster and Marks, 1970). As new information has become available it has supported the authors' original hypothesis and only in one respect is there an apparent conflict between the present paper and a previous report (Shuster, Watson, and Marks, 1967b). The present authors no longer believe that there is evidence of a structural mucosal abnormality in dermatogenic enteropathy. This paper will be concerned mainly with malabsorption of fat, although there is evidence of malabsorption of D-xylose $\subseteq$ (Marks, 1968; Shuster and Marks, 1970) and $\overline{5}$ iron (Marks and Shuster, 1968) and perhaps folate (Kaimis, Summerly, and Giles, personal communication, 1969) and vitamin $B_{12}$ (Shuster and $₹$ Marks, 1970) in some patients with dermatogenic 음 enteropathy.

The interpretation of results of many 'absorption' tests in patients with skin disease is notori-N ously difficult (Knowles, Shuster, and Wells, " 1963; Fry, Shuster, and McMinn, 1965; Doran, Everett, and Welsh, 1966; Shuster, 1967a and b; $心$ Marks and Shuster, 1968; Shuster and Marks, 1970) and will be discussed only briefly.

\section{Patients}

One hundred subjects were studied. They were all inpatients and so, in many of them, the rash was severe and extensive. There was no selection on the basis of gastrointestinal symptoms which in any case were rare (see below). The majority⿳亠二口犬 of patients had eczema or psoriasis, but patients with the rarer dermatoses lichen planus, pityriasis rubra pilaris, and Darier's disease were also studied when they presented to the authors. 
Two patients who had coeliac disease before they developed a rash, patients with collagen vascular diseases and patients with dermatitis herpetiformis, ie, patients who belonged to groups I, III or IV above, were excluded from this study. Patients with rosacea and bullous diseases other than dermatitis herpetiformis were also excluded as at one time it was considered that there might be a special association between these dermatoses and intestinal abnormalities. With these exceptions, patients with rashes were studied consecutively as they were admitted, as long as they were willing and able to collect samples of stools for analysis.

One patient not included in the 100 consecutive patients on account of her coeliac disease was studied separately, as her behaviour seemed to be important in respect of the possible cause of dermatogenic enteropathy.

\section{Methods}

\section{CLINICAL}

All patients were asked about diarrhoea, pale, bulky stools, and weight loss, although it was appreciated that a history of weight loss would be difficult to interpret in patients with generalized eczema and psoriasis who might lose weight for reasons other than malabsorption (Shuster, 1967a and 1968a; Shuster and Marks, 1970).

The extent of the rash was assessed in each patient by clinical examination, and patients were put into one of three categories.

1 Those with erythroderma $(100 \%$ skin surface involved).

2 Those with skin disease of moderate extent (approximately $75-50 \%$ surface involved).

3 Those with skin disease confined to small areas, eg, palms and soles (less than $10 \%$ skin surface involved).

\section{LABORATORY}

Faecal fat excretion was measured in all patients before treatment of the skin, and in 18 of the 34 who had steatorrhoea it was measured again after treatment. It was not usually measured after treatment if it was only marginally raised at the height of the skin disease, and in a few patients with definite steatorrhoea followed up, faecal fat estimations were not possible for various reasons. Treatment consisted only of topical application in five patients of $0 \cdot 2-0.4 \%$ dithranol paste, in three patients of $1 \%$ hydrocortisone, in eight patients of $0.01-0.1 \%$ betamethasone valerate, and in two patients of $0.0025 \%$ fluocinolone acetonide. One patient treated with hydrocortisone was also on a gluten-free diet but all other patients were on a normal ward diet. Four patients were studied in more than one episode of skin disease and in them the faecal fat excretion was measured each time.

In an attempt to elicit the mechanism of the enteropathy urinary indican excretion, bacteriology of the jejunal juice, and pancreatic function were studied in a few patients, and a peroral jejunal mucosal biopsy was taken in all patients in whom it was practicable.

\section{Faecal fat excretion}

This was measured by the method of van de Kamer, ten Bokkel Huinink, and Weyers (1949). With the exception of the patient with coeliac disease referred to above and one other (see Figure 2) who were on gluten-free diets, the patients were kept on an ordinary ward diet known to contain about $100 \mathrm{~g}$ fat per day. Specimens were collected for five days without markers and the result was expressed as the mean of these five-day collections.

\section{Urinary indican}

This was measured in six patients with steatorrhoea by the method of Jaffe (Varley, 1954).

\section{Bacteriological examination of jejunal juice}

Jejunal fluid was obtained with a Shiner capsule (Shiner, Waters, and Gray, 1963) in three patients with steatorrhoea. Blood agar plates and bottles of Robertson's meat medium were inoculated with the fluid and incubated at $37^{\circ} \mathrm{C}$ under aerobic and anaerobic conditions.

\section{Pancreatic function}

Duodenal intubation was carried out in one patient with steatorrhoea and the volume, bicarbonate content, and amylase concentration of the intestinal juice were measured after injection of secretin and pancreozymin.

\section{Jejunal mucosal biopsy}

This was carried out in 46 patients, 13 of whom had steatorrhoea and 23 of whom did not. A Crosby capsule (Crosby and Kugler, 1957) was used and the specimens were processed and classified as described elsewhere (Marks and Shuster, 1970).

\section{Results}

\section{CLINICAL}

Five of the 100 patients complained of diarrhoea: in two it was of many years' standing and in three of recent onset. One patient had pale, bulky stools. Five had lost weight, including the one with pale, bulky stools, who had lost $20 \mathrm{~kg}$ since his eczema became widespread, in spite of developing considerable oedema at the same time. He was excreting $24 \mathrm{~g}$ fat in his stools each day, but the other patients who had lost weight did not have steatorrhoea. 


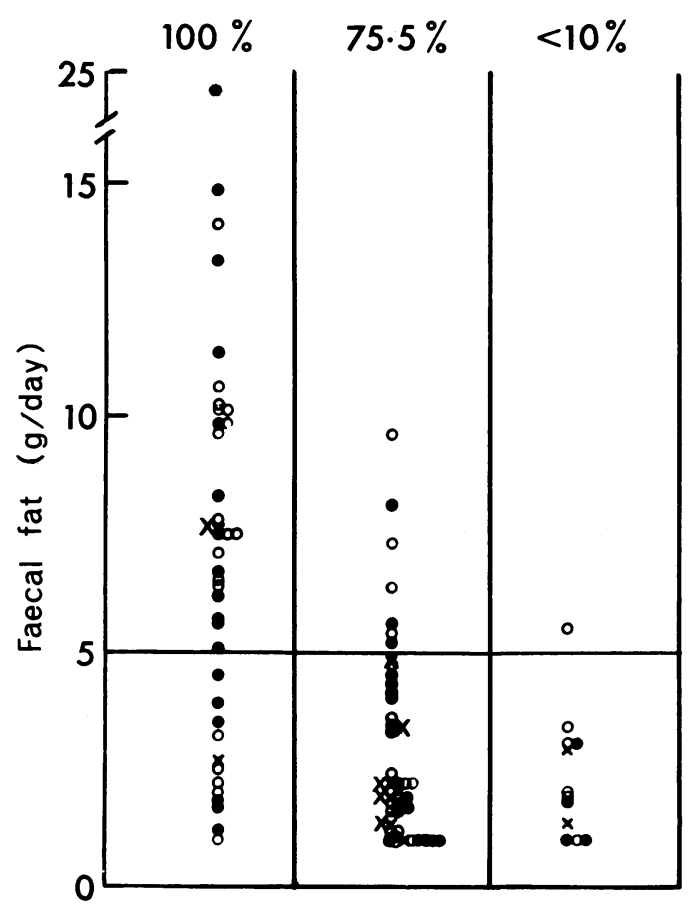

Fig. 1 Faecal fat excretion in patients with psoriasis $(\bigcirc)$, eczema $(\bigcirc)$, and other less common skin diseases $(X)$. The horizontal line indicates the upper limit of normal. The extent of the rash is also shown.

Clinical assessment showed that 41 of the patients had erythroderma, 47 had moderately extensive skin disease, and 12 had skin disease of very limited extent.

\section{FAECAL FAT EXCRETION}

Figure 1 shows that 34 patients were excreting more than $5 \mathrm{~g}$ fat per day in their stools at the height of the skin disease. Patients with eczema and psoriasis were affected in approximately equal numbers and one patient with pityriasis rubra pilaris had steatorrhoea. In the patients with erythroderma, steatorrhoea was very common and often quite severe. It was less common and less severe in those with moderate skin involvement and only one patient with less than $10 \%$ of the skin involved had a faecal fat excretion of more than $5 \mathrm{~g}$ /day (Figure 1). There is a significant difference between the results in those with $100 \%$ surface involvement and those with less extensive skin disease $(t=4.9, P<0.01)$.

\section{RESPONSE TO TREATMENT OF THE SKIN}

Figure 2 shows the faecal fat excretion before and after various topical treatments of the skin in the 18 patients with steatorrhoea studied again. The steatorrhoea improved with response of the rash to treatment in $\mathbf{1 7}$ of the patients and

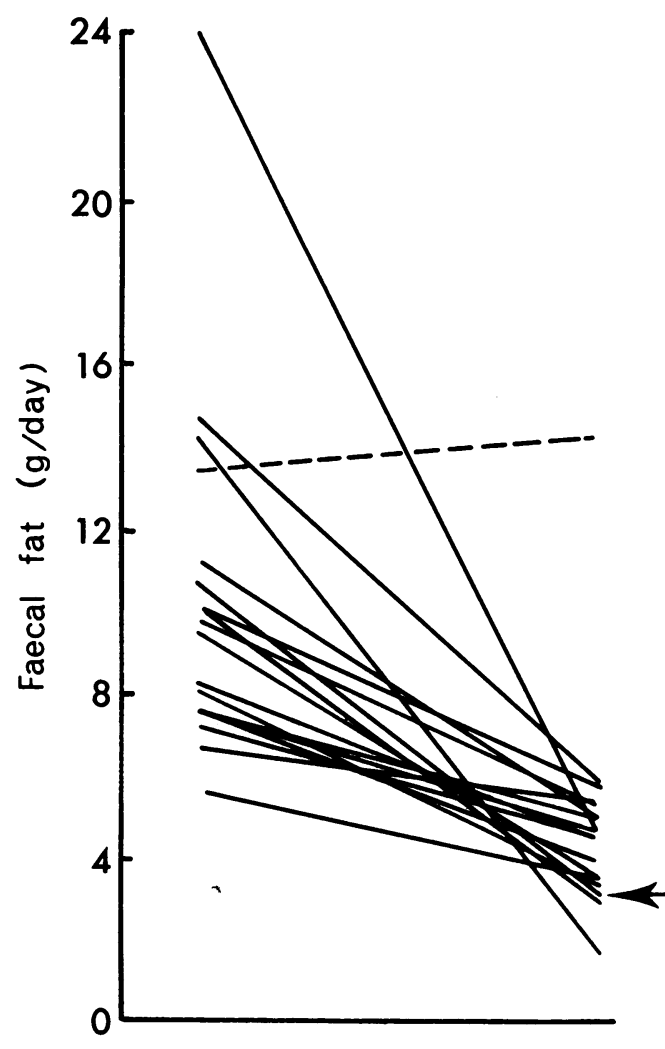

Fig. 2 Faecal fat excretion before and after topical treatment of the skin. The dotted line shows the patient whose rash did not respond to treatment. The arrow indicates the patient who was given a gluten-free diet in addition to local treatment.

this improvement is significant $\left(t=5 \cdot 1, \quad P<\frac{\vec{\sigma}}{3}\right.$ $0.01)$. In the eighteenth patient the steatorrhoea persisted after treatment, but the eczema failed to respond to treatment and was as extensive at the time of his discharge from hospital as when he was admitted. This patient has since been lost to follow up.

The response of the steatorrhoea to treatment $N$ of the skin was often very rapid and was found in patients whose faecal fat excretion was measured $\mathcal{N}^{\circ}$ as little as one or two weeks after the rash had ${ }^{\omega}$ cleared. It bore no relation to the nature of the local application used and was found in those treated with dithranol as well as those in whom corticosteroid ointments were used; thus any possible effect on the bowel of corticosteroid absorbed through the skin is irrelevant.

\section{FAECAL FAT EXCRETION IN SUCCESSIVE} ATTACKS OF SKIN DISEASE

Table I shows that three of the four patients? studied in more than one attack of eczema oro psoriasis developed steatorrhoea in each attack, $\stackrel{\rightleftharpoons}{\rightleftharpoons}$ although their faecal fat excretion returned to normal when the rash remitted. One patient studied in two attacks had steatorrhoea only in 


\begin{tabular}{|c|c|c|c|c|}
\hline \multirow[t]{2}{*}{ Patient } & \multicolumn{4}{|c|}{ Faecal Fat Excretion (g/day) } \\
\hline & Attack & Remission & Attack & Remission \\
\hline $\begin{array}{l}\text { A.B. } \\
\text { M.H. } \\
\text { G.K. } \\
\text { R.H. }\end{array}$ & $\begin{array}{r}9 \cdot 8 \\
5.6 \\
4 \cdot 4 \\
24 \cdot 0\end{array}$ & $\begin{array}{l}5 \cdot 4 \\
4 \cdot 2 \\
\frac{-}{4 \cdot 7}\end{array}$ & $\begin{array}{r}14 \cdot 8 \\
10 \cdot 1 \\
8 \cdot 3 \\
18 \cdot 0\end{array}$ & $\begin{array}{l}- \\
5.2 \\
4.5 \\
-\end{array}$ \\
\hline
\end{tabular}

Table I Faecal fat excretion in successive attacks of skin disease in four patients with eczema and psoriasis

the second, but the rash was not very extensive on the first occasion.

\section{URINARY INDICAN}

This was not increased in four of the six patients (Table II) and, although the method used is only semi-quantitative, failure to find an increased urinary indican in some of the patients with steatorrhoea suggests that coliforms were not present in excessive numbers in the small bowel (Tabaqchali, Okubadejo, Neale, and Booth, 1966). Consequently the steatorrhoea of dermatogenic enteropathy is presumably not due to bacterial overgrowth in the small intestine.

\section{BACTERIAL EXAMINATION OF JEJUNAL} JUICE

Bacterial counts were not done, but the failure to find colonies of coliforms in the patients studied (Table II) again suggests that there is no abnormal bacterial colonisation of the small bowel.

\section{PANCREATIC FUNCTION}

The volume, bicarbonate concentration, and amylase content of the duodenal juice were normal in the patient with dermatogenic enteropathy studied (Table II). This patient had considerable steatorrhoea at the time and the results suggest that this was not due to simple failure of exocrine pancreatic secretion.

\begin{tabular}{lllll}
\hline Patient & $\begin{array}{l}\text { Faecal Fat } \\
\text { Excretion } \\
(\mathrm{g} / \text { day })\end{array}$ & $\begin{array}{l}\text { Jejunal } \\
\text { Bacteriology }\end{array}$ & $\begin{array}{l}\text { Urinary } \\
\text { Indican }\end{array}$ & $\begin{array}{l}\text { Pancreatic } \\
\text { Function }\end{array}$ \\
\hline T.B. & 5.2 & No coliforms & Excess & - \\
W.J. & $6 \cdot 2$ & No coliforms & No excess & - \\
J.Bo. & 6.4 & - & No excess & - \\
G.Kn. & 9.6 & - & Excess & - \\
A.B. & 9.8 & - & No excess & - \\
R.H. & 18.0 & No coliforms & No excess & Normal \\
\hline
\end{tabular}

Table II Urinary indican, jejunal bacteriology, and pancreatic function in six patients with dermatogenic enteropathy

\section{JEJUNAL BIOPSY}

The faecal fat excretion and predominant stereomicroscopic appearance in the 46 patients in whom both were studied is shown in Figure 3. None of the patients had a flat mucosa and so the steatorrhoea was not due to coeliac disease. As a predominantly convoluted musosa occurs in $8 \%$ of the population in Newcastle upon Tyne (Marks and Shuster, 1970), the finding of a convoluted mucosa in three of the patients in the present study is almost certainly a manifestation of this local characteristic. In any case it occurred in patients with and without steatorrhoea (Figure 3). The finding of a normal small bowel mucosal structure in dermatogenic enteropathy is of course in sharp contrast to the state of affairs in patients with dermatitis herpetiformis, two-thirds

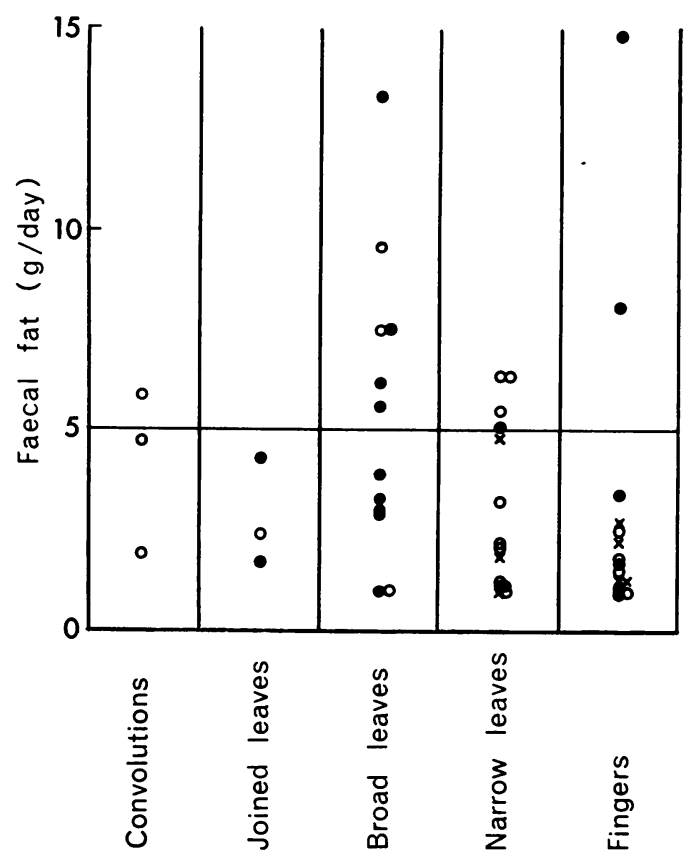

Fig. 3 Faecal fat excretion and predominant jejunal biopsy appearance in patients with skin disease. The horizontal line indicates the upper limit of normal faecal fat excretion. Psoriasis $\bigcirc$, eczema $O$, other skin diseases $\mathrm{x}$.

of whom have a flat or convoluted mucosa (Marks, Shuster, and Watson, 1966; Fraser, Murray, and Alexander, 1967; Fry, Keir, McMinn, Cowan, and Hoffbrand, 1967; Marks, Whittle, Beard, Robertson, and Gold, 1968).

PATIENT WITH COELIAC DISEASE WHO LATER DEVELOPED ERYTHRODERMA This patient was diagnosed as having coeliac disease in 1955 on the basis of a faecal fat excretion of $11 \mathrm{~g} /$ day, a flat mucosa on jejunal biopsy, and a megaloblastic anaemia due to folic acid deficiency. She responded well to a gluten-free diet, and in 1964 while still on the diet she developed erythrodermic eczema. On admission to hospital at that time she was excreting $36 \mathrm{~g}$ fat/ day in the stools. This increase in faecal fat excretion was presumably due to a superimposed 
dermatogenic enteropathy. She was then treated with $15 \mathrm{mg} /$ day prednisone and the improvement in the skin which followed may well have contributed to the subsequent fall to $8.49 \mathrm{~g} /$ day in the faecal fat excretion, though on this occasion the possible effect of prednisone on the bowel cannot be excluded. The ability to develop dermatogenic enteropathy while taking a standard 'gluten-free' diet supports the idea that gluten sensitivity, as usually understood, plays no part in the process.

\section{Discussion}

Steatorrhoea is extremely common in patients with very extensive skin disease. It has been found so far in patients with eczema and psoriasis and in one patient with pityriasis rubra pilaris but there is no reason to suppose it may not occur in other extensive dermatoses. Steatorrhoea may also occur in patients with less extensive skin disease but in general the severity and incidence of the steatorrhoea are related to the extent of the rash. The steatorrhoea disappears rapidly in patients in whom the rash responds to treatment and persists in patients in whom the rash does not respond. Patients studied in more than one attack of skin disease often have been found to have steatorrhoea in more than one attack, in spite of recovery of the small intestine in between. From these observations-the relation of the steatorrhoea to the extent of the rash regardless of the nature of the dermatosis, the response of the bowel as the skin improves, the failure of response when the rash persists, and the recurrence of the steatorrhoea in successive attackswe deduce that the steatorrhoea is due to the skin disease and classifiable in group II.

Bowel symptoms are rare in dermatogenic enteropathy and this is not entirely explained by the mildness of the biochemical abnormality, for some patients without symptoms have considerable steatorrhoea. It is of course well known that a number of patients with coeliac disease also do not have bowel symptoms.

An enteropathy manifest only by malabsorption of fat would be an unusual one and malabsorption of other substances has been studied, but, in patients with skin disease especially, extreme caution is necessary before attributing to malabsorption an abnormality in any of the socalled 'screening tests'. D-xylose tolerance tests, for instance, are abnormal in a large number of patients with skin disease (Fry et al, 1965; Doran et al, 1966) but alterations in renal excretion of the substance, rather than malabsorption, may be responsible for the abnormal results in many cases. Similarly, the decreased absorption of vitamin $B_{12}$ found in some of the patients with dermatogenic enteropathy (Marks, 1968; Shuster and Marks, 1970) may be due to abnormal renal handling of the substance: megaloblastic anaemia due to folate deficiency occurs occasionally in patients who also have dermatogenic enteropathy (Shuster, Marks, and Chanarin, 1967a; Shuster and Marks, 1967), and Figlu excretion after a dose of L-histidine (Knowles et al, 1963), $\overrightarrow{\vec{F}}$ serum folate concentration (Shuster et al, 1967a) and folic acid absorption tests (Kaimis et al, 드 1969) may be abnormal, but in patients with a $\overline{\bar{c}}$ rapidly metabolising epidermis, eg, in psoriasis, $\overparen{\Phi}$ they cannot without further evidence be attributed $\varrho$ to malabsorption. Iron absorption in patients ${ }^{\infty}$ with skin disease may be influenced by depleted $\vec{O}$ iron stores in those of the patients with extensive $\overrightarrow{-}$ scaly dermatoses, but this is rare and the hypo- $\omega^{\circ}$ ferraemia which is so often seen in eczema and psoriasis is usually metabolic and not due to iron deficiency from any cause (Marks, 1968; Marks.and Shuster, 1968). Hypocalcaemia has been iे $^{+}$ seen in association with dermatogenic entero- $\mathrm{CN}^{-}$ pathy (Copeman and Bold (for Wallace), 1965) buto the hypocalcaemia of extensive skin disease is more often due to hypoalbuminaemia which also occurs (Shuster and Wilkinson, 1963; Shustero and Marks, 1970).

In spite of these difficulties it has been shown that in some patients with dermatogenic enteropathy malabsorption of substances other than fat may occur. Malabsorption of D-xylose (Marks, 1968; Shuster and Marks, 1970), iron (Marks and Shuster, 1968), and calcium (Copeman and Bold (for Wallace), 1965) certainly occurs and malab- $\_$ sorption of folate probably does (Kaimis et al, $\overrightarrow{\mathrm{O}}$ 1969; Shuster and Marks, 1970). As dermato-3 genic enteropathy is shortlived, malabsorption of essential minerals and vitamins is unlikely to lead to serious deficiencies except in those with chronico or relapsing widespread dermatoses.

The failure to find a flat mucosa in patients with dermatogenic enteropathy means that it is quite unlike the enteropathy induced by gluten. The incidence of a convoluted mucosa in the patients 0 with dermatogenic enteropathy is no greater than in our local control population (Marks ando Shuster, 1970) and so there is no special association of this type of mucosal appearance with the enteropathy. Further evidence that gluten sensi- $N$ tivity is not the cause comes from a patient who N developed dermatogenic enteropathy while on a gluten-free diet. From the information available it seems unlikely that either an overgrowth of ${ }_{\mathscr{D}}^{-}$ coliforms in the small bowel or failure of exocrine pancreatic secretion is the cause of dermatogenic 0 enteropathy. We know that renal blood flow is decreased (Shuster and Marks, 1970) in patients with erythroderma whose skin takes more than $\frac{\mathbb{}}{\varnothing}$ its fair share of the cardiac output (Fox, Shuster, $\bar{O}$ Williams, Marks, Goldsmith, and Condon, $1965 ;$ Shuster and Marks, 1970) and we have consideredo that a decreased blood flow to the small bowel might be the explanation of dermatogenico enteropathy, but the finding of steatorrhoea in ${ }^{+}$ patients with less extensive skin disease, whose skin blood flow is unlikely to be very different 
from normal, makes such an explanation inadequate. The possibility of a specific enzyme defect in the small intestinal mucosa was investigated at one time (Shuster et al, 1967b) but it is now known that the enzyme abnormalities we found are not confined to patients with dermatogenic enteropathy. Deficiency of an essential metabolite has to be considered. Folate deficiency is common in patients with skin disease, mainly as a result of increased requirements, but we have already shown that there is no correlation between serum folate concentration and steatorrhoea (Shuster et al, 1967a): true iron deficiency is rare and the hypoferraemia of skin disease is usually metabolic and not associated with mucosal changes (Marks, 1967; Marks and Shuster, 1968). We have no information about bile salt metabolism in patients with dermatogenic enteropathy. It is tempting to postulate that an inflamed skin produces pharmacologically active substances which are responsible for the many systemic effects of skin disease (Shuster, 1967a), including dermatogenic enteropathy, and an animal model is being set up at present to investigate this possibility.

Where does dermatogenic enteropathy lie in relation to enteropathies produced by other chronic disease? It differs from that described in carcinomata (Creamer, 1964) in that it is not associated with a flat mucosa. It perhaps most resembles the reversible steatorrhoea found in $33 \%$ of patients with ulcerative colitis, though in this instance the authors (Salem and Truelove, 1965) were not able to exclude direct involvement of the small bowel by the primary disease. The malabsorption of folate found in patients with heart failure (Hyde and Loehry, 1968) may be comparable too. With these possible exceptions dermatogenic enteropathy would appear to be unique in the frequency of its occurrence but systematic studies in large numbers of patients with other chronic disease may show that this is not so.

We have referred to one peculiarity of the local population, namely, their increased chance of having a convoluted mucosa. Is it possible that this special population in Newcastle upon Tyne is also particularly prone to develop dermatogenic enteropathy? This seems unlikely now that another series has been reported (Kaimis 1969), this time from Stoke-on-Trent, with an incidence of steatorrhoea very similar to that in our own patients.

Presumably dermatogenic enteropathy occurred before 1965 and our original publication (Shuster and Marks, 1965) merely described something which already existed under another name. It seems probable that it was misdiagnosed as gluten-induced enteropathy which had produced a rash, and it is extremely important, not least from the patient's point of view, that the two conditions should be separated. It is of course well known that malabsorption may produce eczematous and psoriasiform rashes (MansonBahr and Willoughby, 1930; Bennett, Hunter, and Vaughan, 1932; Cooke, Peeney, and Hawkins, 1953; Badenoch, 1960; Wells, 1962). These are usually less extensive than those producing dermatogenic enteropathy though complete erythroderma has been described (Dent and Garrets, 1960). Hyperpigmentation is common (Manson-Bahr and Willoughby, 1930; Thaysen, 1935; Konstam and Gordon, 1936) though this is not a distinguishing feature, as patients with dermatogenic enteropathy may become hyperpigmented as indeed do many patients with inflammatory dermatoses who do not have steatorrhoea. The most useful distinction is jejunal biopsy, and gluten-induced enteropathy with a rash should not be diagnosed without a flat jejunal mucosa. In the differentiation of dermatogenic enteropathy from tropical sprue which has produced a rash, even jejunal biopsy is unlikely to help, and diagnosis has to rest on the ultimate response of the steatorrhoea to treatment of the rash. A gluten-free diet should not be used as a diagnostic tool as it will only confuse the issue should it be given to a patient with dermatogenic enteropathy. Eczema and psoriasis are diseases with remissions and exacerbations even in the absence of treatment, consequently if a remission coincides with the giving of a gluten-free diet the steatorrhoea will improve as the rash improves and credit will be given erroneously to the diet. No special diet is needed in dermatogenic enteropathy and it is bad medicine to condemn a patient to one for the rest of his life for no good reason. In practice he rarely requires anything more than treatment of the rash, though patients with chronic, relapsing disease may occasionally need replacement therapy with folic acid, vitamin $B_{12}$, vitamin $\mathrm{D}$, calcium, and iron.

The work was financed by a grant from the Medical Research Council for which we are grateful. We wish also to acknowledge help from the dermatologists of the Newcastle upon Tyne Hospitals and North-East Region who referred patients to us; from Professor A. L. Latner in whose laboratory most of the biochemical estimations were done, and also from Dr D. A. Birkett, Dr A. J. Watson, Dr J. Kennedy, and Miss Diane James.

\section{References}

Badenoch, J. (1960). Steatorrhoea in the adult. Brit. med. J., 2, 879-887.

Bennett, T. I., Hunter, D., and Vaughan, J. M. (1932). Idiopathic steatorrhoea (Gee's disease). Quart. J. Med., n.s., 1, 603677.

Cooke, W. T., Penney, A. L. P., and Hawkins, C. F. (1953). Symptoms, signs, and diagnostic features of idiopathic steatorrhoea. Quart. J. Med. n.s., 22, 59-77.

Copeman, P. W. M., and Bold, A. M. (for Wallace, H. J.) (1965). Generalized pustular psoriasis (von Zumbusch) with episodic hypocalcaemia. Proc. roy. Soc. Med., 58, 425-427.

Creamer, B. (1964). Malignancy and the small-intestinal mucosa. Brit. med. J., 2, 1435-1436. 
Crosby, W. H., and Kugler, H. W. (1957). Intraluminal biopsy of the small intestine: the intestinal biopsy capsule. Amer .J. dig. Dis., 2, 236-241.

Dent, C. E., and Garretts, M. (1960). Skin changes in hypocalcaemia. Lancet, 1, 142-146.

Doran, C. K., Everett, M. A., and Welsh, J. D. (1966). The d-xylose tolerance test. Arch. Derm., 94, 574-576.

Fox, R. H., Shuster, S., Williams, R., Marks, J., Goldsmith, R., and Condon, R. E. (1965). Cardiovascular, metabolic, and thermoregulatory disturbances in patients with erythrodermic skin diseases. Brit. med. J., 1, 619-622.

Fraser, N. G., Murray, D., and Alexander, J. O'D. (1967) Structure and function of the small intestine in dermatitis herpetiformis. Brit. J. Derm., 79, 509-518.

Fry, L., Keir, P., McMinn, R. M. H., Cowan, J. D., and Hoffbrand, A. V. (1967). Small-intestinal structure and function and haematological changes in dermatitis herpetiformis. Lancet, 2, 729-734.

Fry, L., Shuster, S., and McMinn, R. M. H. (1965). D-xylose absorption in patients with eczema. Brit. med. J., 1, 967968.

Hyde, R. D., and Loehry, C. A. E. H. (1968). Folic acid malabsorption in cardiac failure. Gut, 9, 717-721.

Kaimis, J., Summerly, R., and Giles, C. (1969). Personal communication.

Knowles, J. P., Shuster, S., and Wells, G. C. (1963). Folic-acid deficiency in patients with skin disease. Lancet, 1, 11381139.

Konstam, G., and Gordon, H. (1936). Idiopathic steatorrhoea with skin lesions and megalocytic anaemia. Proc. roy. Soc. Med., 29, 629-631.

Manson-Bahr, P. H., and Willoughby, H. (1930). Studies on sprue with special reference to treatment. Quart. J. Med., 23, $411-442$.

Marks, J. (1967). Iron metabolism in skin disease. J. roy. Coll. Phycns, Lond., 1, 367-372.

Marks, J. (1968). Systemic effects of skin disease with particular reference to the small intestine. DM Thesis, University of Oxford.

Marks, J., and Shuster, S. (1968). Iron metabolism in skin disease. Arch. Derm. 98, 469-475.

Marks, J., and Shuster, S. (1970). Small-intestinal abnormalities in various dermatoses-fact or fancy? Gut, 11, 281-291.

Marks, J., Shuster, S., and Watson, A. J. (1966). Small-bowel changes in dermatitis herpetiformis. Lancet, 2, 1280-1282.

Marks, J., Shuster, S., and Watson, A. J. (1970). Dermatogenic enteropathy. In Proc. 8th int. Congr. Gastroent., 1968. Modern Gastroenterology, ed. O. Gregor \& O. Riedl, p. 795.
Marks, R., Whittle, M. W., Beard, R. J., Robertson, W. B., and Gold, S. C. (1968). Small-bowel abnormalities in dermatitis herpetiformis. Brit. med. J., 1, 552-555.

Salem, S. N., and Truelove, S. C. (1965). Small-intestinal and $\Omega$ gastric abnormalities in ulcerative colitis. Brit. med. J., 1, 827-831.

Shiner, M., Waters, T. E., and Gray, J. D. A. (1963). Culture studies of the gastrointestinal tract with a newly devised capsule. Gastroenterology, 45, 625-632.

Shuster, S. (1967a). Systemic effects of skin disease. Lancet, 1, $\frac{}{\sigma}$ 907-912.

Shuster, S. (1967b). Skin diseases and malabsorption: a re- $\supset$

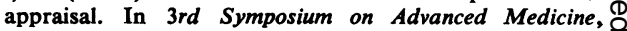
Royal College of Physicians, London, edited by A. M. (1) Dawson, pp. 349-361. Pitman, London.

Shuster, S. (1968a). In discussion to Fry, L., and Russell, B. F., 'Multiple primary carcinomata in idiopathic steatorrhoea'. Proc. roy. Soc. Med., 61, 242.

Shuster, S. (1968b). Dermatogenic enteropathy. N.Y. St. J. Med., $\vec{\omega}$ 68, 3160-3165.

Shuster, S., and Marks, J. (1965). Dermatogenic enteropathy: a new cause of steatorrhoea. Lancet, 1, 1367-1368.

Shuster, S., and Marks, J. (1967). Dermatopathic anaemia. Brit. J. Derm., 79, 393-397.

Shuster, S., and Marks, J. (1970). In Systemic Effects of Skin Disease. Heinemann, London. In press.

Shuster, S., Marks, J., and Chanarin, I. (1967a). Folic acid N deficiency in patients with skin disease. Brit. J. Derm., 79, 응 398-402.

Shuster, S., Watson, A. J., and Marks, J. (1967b). Small intestine in psoriasis. Brit. med. J., 3, 458-460.

Shuster, S., and Wilkinson, P. (1963). Protein metabolism in exfoliative dermatitis and erythroderma. Brit. J. Derm., 75, 344-353.

Tabaqchali, S., Okubadejo, O. A., Neale, G., and Booth, C. C. (1966). Influence of abnormal bacterial flora on small intestinal function. Proc. roy. Soc. Med., 59, 1244-1246.

Thaysen, T. E. H. (1935). Ten cases of idiopathic steatorrhoea. Quart. J. Med., n.s., 4, 359-395.

van de Kamer, J. H., ten Bokkel Huinink, H., and Weyers, H. A. (1949). Rapid method for the determination of fat in feces. J. biol. Chem., 177, 347-355.

Varley, H. (1954). Practical Clinical Biochemistry, p. 328. Heinemann, London.

Wells, G. C. (1962). Skin disorders in relation to malabsorption. Brit. med. J., 2, 937-943. 